LBL - 36166

$\mathrm{UC}-426$

Paper submitted to the

International Conference on Metallurgical Coatings and Thin Films

ICMCTF-95

April 24-28, 1995, San Diego, CA

\title{
Formation of Metal Oxides by Cathodic Arc Deposition
}

S. Anders, A. Anders, M. Rubin, Z. Wang, S. Raoux, F. Kong, and I. G. Brown

Lawrence Berkeley Laboratory, University of California, Berkeley, CA 94720

March 1995

This work was supported by the U. S. Department of Energy, Division of Advanced Energy Projects, and the Assistant Secretary for Energy Efficiency and Renewable Energy, Office of Building Technologies, Building Systems and Materials Division of the U.S. Department of Energy, under Contract NO. DE-AC03-76SF00098.

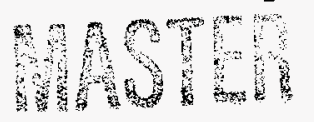


89 regred paper 


\section{DISCLAIMER}

This report was prepared as an account of work sponsored by an agency of the United States Government. Neither the United States Government nor any agency thereof, nor any of their employees, make any warranty, express or implied, or assumes any legal liability or responsibility for the accuracy, completeness, or usefulness of any information, apparatus, product, or process disclosed, or represents that its use would not infringe privately owned rights. Reference herein to any specific commercial product, process, or service by trade name, trademark, manufacturer, or otherwise does not necessarily constitute or imply its endorsement, recommendation, or favoring by the United States Government or any agency thereof. The views and opinions of authors expressed herein do not necessarily state or reflect those of the United States Government or any agency thereof. 


\section{DISCLAIMER}

Portions of this document may be illegible in electronic image products. Images are produced from the best available original document. 


\title{
Formation of Metal Oxides by Cathodic Arc Deposition
}

\author{
S. Anders, A. Anders, M. Rubin, Z. Wang, S. Raoux, F. Kong, and I. G. Brown \\ Lawrence Berkeley Laboratory, University of California, Berkeley, CA 94720
}

\begin{abstract}
Metal oxide thin films are of interest for a number of applications. Cathodic arc deposition, which is an established and industrially applied technique for the formation of nitrides (e.g. TiN), can also be used for metal oxide thin film formation. A cathodic arc plasma source with the desired cathode material is operated in an oxygen atmosphere of appropriate pressure, and metal oxides of various stoichiometric composition can be formed on different substrates. We report here on a series of experiments on metal oxide formation by cathodic arc deposition for different applications. Black copper oxide has been deposited on accelerator components to increase the radiative heat transfer between the parts. Various metal oxides such as tungsten oxide, niobium oxide, nickel oxide and vanadium oxide have been deposited on ITO glass to form electrochromic films for window applications. Tantalum oxide films are of interest for replacing polymer electrolytes. Optical waveguide structures can be formed by refractive index variation using oxide multilayers. We have synthesized multilayers of $\mathrm{Al}_{2} \mathrm{O}_{3} / \mathrm{Y}_{2} \mathrm{O}_{3} / \mathrm{Al}_{2} \mathrm{O}_{3} / \mathrm{Si}$ as possible basic structures for passive optoelectronic integrated circuits, and $\mathrm{Al}_{2}-\mathrm{x}_{\mathrm{x}} \mathrm{O} 3$ thin films with a variable Er concentration which is a potential component layer for the production of active optoelectronic integrated devices such as amplifiers or lasers at a wavelength of $1.53 \mu \mathrm{m}$. Aluminum and
\end{abstract}


chromium oxide films have been deposited on a number of substrates to impart improved corrosion resistance at high temperature. Titanium sub-oxides which are electrically conductive and corrosion resistant and stable in a number of aggressive environments have been deposited on various substrates. These sub-oxides are of great interest for use in electrochemical cells. Common features of all these depositions are the high deposition rate typical for cathodic arc deposition, the good adhesion of the films due to the high metal ion energy, and the advantage of an environmentally clean method in comparison to wet-chemical oxide formation techniques. 


\section{Introduction}

Cathode spots of vacuum arc discharges are sources of highly ionized, dense plasma of the cathode material. Vacuum arc plasma sources based on this type of discharge have been used to deposit various metal films, alloy films, and amorphous hard carbon films of high quality, in particular if the sources are equipped with macroparticle filters to remove the solid debris which is formed at the cathodes of the sources along with the plasma. If these sources are operated in a gaseous atmosphere such as nitrogen or oxygen, chemical compounds can be formed. The cathode spot mechanism is similar, and the sources are then more appropriately called cathodic arc plasma sources. The formation of nitrides such as, e.g., TiN, $\mathrm{HfN}, \mathrm{ZrN}$, and also (Ti, $\mathrm{Al}) \mathrm{N}$ by cathodic arc deposition is an established technique and has many applications, in particular hard coatings for tools. The formation of oxides is possible in the same way by operating a cathodic arc metal plasma source in an oxygen environment $[1,2]$. This technique has a number of advantages in comparison to other oxide formation techniques. The method is high rate, environmentally clean, and flexible in the sense that by varying plasma production and gas pressure oxides of various stoichiometric ratio can be formed. By operating two or more sources simultaneously or by using alloy cathodes it is possible to deposit oxides containing more than one metal species. A further advantage is the possible combination of cathodic arc deposition of oxides with various biasing techniques of the substrates, which allows one to influence the metal ion energy and thereby to modify the substrate-film interface and the film properties.

In the present paper we report on experiments which were performed to deposit metal oxides of various types for a number of applications. We describe the plasma source and macroparticle filter designs, their application to metal oxide formation, and the properties of the deposited oxide films. 


\section{Cathodic Arc Plasma Sources and Macroparticle Filters}

A variety of cathodic arc plasma sources have been designed and operated depending on the specific application. Our smallest source has a cathode diameter of $3 \mathrm{~mm}$ and is operated in a pulsed mode (typical pulse length $250 \mu \mathrm{s}, 1-5 \mathrm{~Hz}$ ); it is suited for the deposition of monolayers up to films of $10 \mathrm{~nm}$. Our largest source has a cathode diameter of $50 \mathrm{~mm}$, is water-cooled, can operate continuously, and is designed for the deposition of thick films in the micron range on large substrates. For high-quality applications, macroparticle-free films are required, and all our sources can be combined with 90 degrees bent magnetic macroparticle filters of various sizes. For other applications a slight macroparticle contamination of the films can be tolerated and the sources are operated without a filter. The sources and/or the substrates can be mounted on moveable feedthroughs which allows the coating of complex or large substrates. A detailed description of sources and filters can be found elsewhere [3-7].

We apply a pulse biasing technique for many depositions in order to enhance the adhesion and to influence the film properties. The substrates which are immersed in the plasma are repetitively pulse biased to a negative voltage. During the bias pulses ions are extracted from the plasma, accelerated and implanted into the substrates whereas between the pulses low-energy deposition takes place. This method is called Plasma Immersion Ion Implantation and Deposition and is described in detail elsewhere $[8,9]$.

\section{Applications}

\subsection{Formation of black $\mathrm{CuO}$ films for increased heat transfer}

The radiation properties of $\mathrm{CuO}$ are close to those of an ideal black body making it a good coating for applications of enhanced radiation heat transfer. The longitudinal feedback kicker of the Advanced Light Source at Lawrence Berkeley Laboratory needs additional cooling because the 
kicker electrodes are heated by currents induced in the structure by the electron beam; and they transfer this heat mainly by radiation to the kicker housing. The kicker is made from aluminum and consists of four RF electrode pairs inside a kicker housing which is a tube of $1 \mathrm{~m}$ length and an inner diameter of $15 \mathrm{~cm}$. A black coating $\mathrm{CuO}$ on the kicker surfaces can increase the radiation heat transfer considerably. Copper oxide was deposited using a cathodic arc plasma source with a copper cathode ( $50 \mathrm{~mm}$ diameter) operated in an oxygen atmosphere at a pressure of $40 \mathrm{~Pa}$. The arc current was $120 \mathrm{~A}$, the arc duration $250 \mathrm{~ms}$, and the arc repetition rate $0.5 \mathrm{~s}^{-1}$. For this particular deposition we used a plasma source without anode and configured the substrate as the anode for coating the outside of kicker electrodes as well as for coating the inside of the kicker housing. In this application a slight contamination of the $\mathrm{CuO}$ film by macroparticles can be tolerated as long as the film appears black because a few micron-size copper macroparticles do not influence the RF behavior of the device. The kicker electrodes were mounted on a movable vacuum feedthrough to allow rotation and longitudinal movement. The inside of the kicker housing was coated by moving the plasma source through the bore of the housing. Areas which were not to be coated were covered by stainless steel masks. Figure 1 shows one of the electrodes and the housing after deposition and removal of the masks. The average deposition rate was $5 \mathrm{~nm} / \mathrm{s}$ over an area of $100 \mathrm{~cm}^{2}$ for the deposition of the electrodes, and $20 \mathrm{~nm} / \mathrm{s}$ over an area of $100 \mathrm{~cm}^{2}$ for the inside of the kicker housing.

The CuO films were characterized by different methods to verify their chemical composition and structure, adhesion, RF behavior and UHV compatibility. The chemical composition and thickness of the films was determined by Rutherford Backscattering Spectrometry (RBS). The films were found to be slightly oxygen-rich with a nominal composition of $\mathrm{CuO}_{1.23}$ and a thickness of $5 \mu \mathrm{m}$. The crystal structure of the films was studied by X-ray diffraction (XRD) in the Bragg geometry using the $\mathrm{Cu} K \alpha$ line $(\lambda=0.154 \mathrm{~nm})$. XRD results show low diffraction peak intensities of the $\mathrm{CuO}$ phase, with broad $\mathrm{CuO}$ diffraction peaks indicating that the $\mathrm{CuO}$ grain size in this film is small. Because no diffraction peaks of other copper oxide phases are present, it is believed that this film is mostly amorphous with some small grains of crystalline $\mathrm{CuO}$. 
Adhesion was tested using a pull tester. The pull strength necessary to remove the CuO films from the aluminum substrates exceeded $60 \mathrm{MPa}$ which was the internal strength of the epoxy. The coated kicker parts were vacuum baked twice in a furnace at a temperature of $150^{\circ} \mathrm{C}$ for 8 hours. No degradation of the film quality was observed after vacuum baking. The kicker was tested for RF performance before and after $\mathrm{CuO}$ coating, and the transmission loss was identical in both cases. Impedance measurements from $500 \mathrm{MHz}$ to $26 \mathrm{GHz}$ also showed no significant differences indicating that the coating is transparent to RF radiation and well suited for coating of RF devices. Heating tests were performed with CuO-coated aluminum parts which resembled the kicker geometry. When uncoated, cleaned aluminum parts were used and the temperature of the inner electrodes increased asymptotically by up to $150^{\circ} \mathrm{C}$ at a heating power of 8 Watts; this temperature increase is not acceptable for kicker operation. After $\mathrm{CuO}$ coating of the parts the temperature rise was only $50^{\circ} \mathrm{C}$ which is a value that can be tolerated during kicker operation. The test demonstrates the successful enhancement of thermal radiation heat transfer from the inner electrodes to the outer housing by increased radiation from the black surfaces of the parts. The kicker was assembled and installed at the Advanced Light Source, and a base pressure of better than $10^{-8} \mathrm{~Pa}$ has been reached. The experiment is described in detail elsewhere [10].

\subsection{Formation of electrochromic oxide films}

Metal oxides are used in various applications for windows such as spectrally selective coatings and electrochromic windows. Electrochromic windows are multilayer structures of various types containing different metal oxide layers. A typical electrochromic device consists of a structure like glass/transparent conductor/cathodic electrochromic electrode/ionic conductor/anodic electrochromic electrode/transparent conductor/glass. Tin oxide or indium tin oxide (ITO) films are transparent and conducting; and they act as contacts in these structures. Switching elements of the structures change reversibly from transparent to colored when ions are injected into or extracted from these films. Some metal oxides such as tungsten oxide, titanium oxide, niobium oxide or 
vanadium oxide show a cathodic coloration, whereas other oxides such as nickel oxide or cobalt oxide show anodic coloration. The ion conductors in complete solid state devices are also relatively thick oxides such as tantalum oxide and lithium niobate.

We have applied the method of cathodic arc deposition to form oxides of tungsten, nickel, vanadium, niobium, and tantalum thin films on various substrates. Plasma sources with $25 \mathrm{~mm}$ cathode diameter have been operated in pulsed mode with and without macroparticle filters. Typical arc current was $300 \mathrm{~A}$, arc duration $5 \mathrm{~ms}$, and arc repetition rate $1 \mathrm{~s}^{-1}$. The sources were operated at oxygen pressures between 4 and $10 \mathrm{~Pa}$. The substrates were glass and ITO-coated glass. The average deposition rate was $0.1 \mathrm{~nm} / \mathrm{s}$. The substrates were not cooled during the deposition. The exposure to the plasma lead to a temperature rise of the substrates during deposition up to about $100^{\circ} \mathrm{C}$ which promotes the formation of polycrystalline films. Figure 2 shows as an example the switching characteristics of a $\mathrm{WO}_{3}$ film on ITO glass. This $\mathrm{WO}_{3}$ film was cycled in $0.1 \mathrm{M} \mathrm{H}_{2} \mathrm{SO}_{4}$ between -0.8 and $0.8 \mathrm{~V}$ at a rate of $20 \mathrm{mV} / \mathrm{sec}$. The transmittance drops in the infrared for the bleached state, characteristic of a film that has been crystallized by temperature or exposure to energetic bombardment [11]. The high energies of particles arriving in cathodic arc deposition combined with an elevated substrate temperature apparently tend to form more crystalline films of $\mathrm{WO}_{3}$ in comparison to evaporation or sputtering. This tendency is an advantage for cathodic-arc deposition because crystalline films have higher infrared reflectivity which is desired for energy control application [12].

\subsection{Formation of films for optoelectronic integrated circuits}

A new generation of optoelectronic integrated circuits combines devices implementing optical functions in a guided wave structure with electronic semiconductor devices formed on the same substrate. The dielectric waveguide structures are based on multilayer thin film technology. A sandwich is formed in which the central guiding film is of higher refractive index than the

surrounding material. Possible oxide combinations for passive waveguides are, e.g. 
yttrium/aluminum oxide based structures. The refractive index difference between $\mathrm{Al}_{2} \mathrm{O}_{3}$ and $\mathrm{Y}_{2} \mathrm{O}_{3}$ is high (10\%), and the index profile can be tailored by atomic mixing of $\mathrm{Al}$ and $\mathrm{Y}$. Passive optoelectronic components perform functions like phase matching, wave coupling, deflection, splitting, filtering, and focusing [13]. By doping the guiding region with optically active impurities, components such as amplifiers and lasers can be fabricated $[14,15]$. Depending on the kind of active impurity, integrated amplifiers and lasers can be generated for a wide range of wavelengths. An important application is the formation of $1.53 \mu \mathrm{m}$ lasers by doping the waveguide with Er ions. This wavelength of $1.53 \mu \mathrm{m}$ corresponds to the optical window for minimum loss in silica-based optical fiber transmission.

We have formed $\mathrm{Al}_{2} \mathrm{O}_{3}$ and $\mathrm{Y}_{2} \mathrm{O}_{3}$ thin films with appropriate stoichiometric ratio on silicon substrates by operating filtered aluminum and yttrium sources in an oxygen atmosphere. These films are the basic elements for passive devices whereas $\mathrm{Er}$-doped aluminum oxide $\mathrm{Al}_{2-\mathrm{x}} \mathrm{Er}_{\mathrm{x}} \mathrm{O}_{3}$ films are required for active elements. Doping of $\mathrm{Al}_{2} \mathrm{O}_{3}$ with erbium was performed in two different ways. One approach was to use two filtered arc sources (one $\mathrm{Al}$ and one $\mathrm{Er}$ source) directed towards the same substrate which were triggered alternately. The Er concentration was controlled by setting the pulse lengths of the two sources in the required ratio taking the different deposition rates of $\mathrm{Al}$ and $\mathrm{Er}$ into account. The second approach is the application of an aluminum/erbium compound cathode in a single plasma source.

The $1.53 \mu \mathrm{m}$ emission of erbium originates from the ${ }^{4} I_{13 / 2^{-4}} I_{15 / 2}$ intra $4 f^{11}$ shell transition of $\mathrm{Er}^{3+}$ ions. As this orbital is well screened by outer closed shells $5 s^{2}$ and $5 \mathrm{p}^{6}$ it is relevant to note that the emission wavelength depends neither on the host matrix nor on its temperature. Due to ErEr coupling effects however the concentration of erbium in the material plays an important role. As the highest concentration of active center must be reached, a balance must be found in dealing with the excitation efficiency, the cross-relaxation mechanisms, the up-conversion and the selfquenching phenomena [16]. Thus the erbium concentration must be optimized. For Er-doped dielectric materials, this optimum concentration is three orders of magnitude greater than for erbium-doped classical semiconductors [17]. In the case of erbium doped aluminum oxide thin 
films, the concentration of erbium that can be included without reaching the self-quenching threshold is as high as $x=0.45$. Figure 3 shows the photoluminescence spectrum at room temperature of a $300 \mathrm{~nm}$ thick $\mathrm{Al}_{1.55} \mathrm{Er}_{0.45} \mathrm{O}_{3} / \mathrm{Si}$ sample. This film was deposited at room temperature using two separate $\mathrm{Er}$ and $\mathrm{Al}$ sources (cathode diameter $6 \mathrm{~mm}$ ) in an oxygen atmosphere of $2 \mathrm{~Pa}$. Both sources operated at an arc current of $300 \mathrm{~A}$. The erbium source pulse duration was $0.5 \mathrm{~ms}$, the aluminum source pulse duration was $5 \mathrm{~ms}$. After deposition the samples were annealed in air at $\mathrm{T}=600^{\circ} \mathrm{C}$ for 1 hour.

\subsection{Formation of $\mathrm{Al}_{2} \mathrm{O}_{3}$ films for improved corrosion resistance at high temperature}

Protection from corrosion and environmental effects arising from deleterious reactions with gases and condensed products is required for advanced high-temperature materials. Stable surface oxides which are well-adhered to the substrate and retain their mechanical stability after repeated temperature cycling are desired coatings to protect various materials such as metals, alloys or compounds.

We have explored the formation of $\mathrm{Al}_{2} \mathrm{O}_{3}$ and $\mathrm{Cr}_{2} \mathrm{O}_{3}$ films by cathodic arc deposition on a variety of substrates such as stainless steel, $\mathrm{SiC}$, and an iron aluminum alloy. The films were deposited at pressures between $0.5-2.5 \mathrm{~Pa}$, a plasma source (cathode diameter $6 \mathrm{~mm}$ ) with filter was used at an arc current of $250 \mathrm{~A}$, an arc duration of $5 \mathrm{~ms}$ and an arc repetition rate of $1 \mathrm{~Hz}$. A pulsed bias voltage of $-2 \mathrm{kV}$ with a pulse duration of $2 \mu \mathrm{s}$ and a pulse off-time of $6 \mu$ s was applied to the substrates. The substrates were mounted on a water-cooled sample holder.

As deposited at room temperature, the films are almost amorphous. Figure 4 shows an XRD spectrum of an $\mathrm{Al}_{2} \mathrm{O}_{3}$ film on an $\mathrm{FeAl}$ substrate. Figure 5 shows the spectrum of the same film after heating for 16 hours at a temperature of $1000^{\circ} \mathrm{C}$. The most stable form of aluminum oxide, $\alpha-\mathrm{Al}_{2} \mathrm{O}_{3}$ has been formed. Similar results have been obtained for $\mathrm{Cr}_{2} \mathrm{O}_{3}$ films on $\mathrm{SiC}$. The adhesion of the films was investigated using a pull tester before and after heating; in all cases the pull strength was greater than $60 \mathrm{MPa}$, which was the limit of our pull tester. 


\section{Formation of titanium sub-oxides for electrochemical cells}

Magnéli phase sub-oxides of titanium which exist in the composition range between $\mathrm{TiO}_{2}$ and $\mathrm{Ti}_{2} \mathrm{O}_{3}[18]$ have been reported as an electrically conductive and corrosion-resistant electrode material with very little intrinsic electrocatalytic activity for most electrochemical reactions. It is therefore a potentially useful electrode material for alkaline-electrolyte batteries. It is expected that a composite electrode configuration would suppress unwanted parasitic oxygen evolution and thus improve the coulombic efficiency of nickel oxide electrodes. In addition, the high overpotential for the oxygen evolution reaction on the surface coating is beneficial to the formation of higher-valence states of nickel oxides, which leads to a better electrode specific capacity for battery application. Recently non-porous titanium sub-oxide ceramic plates have become available commercially. However, the traditional fabrication technology based on reduction of titanium dioxide at temperatures above $1000^{\circ} \mathrm{C}$ limits its application as a composite electrode material.

By use of the cathodic arc technique, titanium sub-oxide has been deposited on the surface of nickel oxide electrodes. A titanium cathodic arc plasma source with a cathode diameter of $6 \mathrm{~mm}$ was used in a pulsed mode at a current of $200 \mathrm{~A}$, an arc duration of $5 \mathrm{~ms}$, and an arc repetition rate of $1 \mathrm{~Hz}$. A magnetic macroparticle filter was attached to the plasma source, and the source was operated in an oxygen atmosphere of 1-2 $\mathrm{Pa}$. A pulsed bias voltage of $-2 \mathrm{kV}$ with a pulse duration of $2 \mu$ s and a pulse off-time of $6 \mu$ s was applied to the substrates. Sub-oxide films have been deposited on glass, silicon, and metal substrates. The film thickness was about $200 \mathrm{~nm}$. The deposited films were dark blue to black and had a resistivity of $0.15 \Omega \mathrm{cm}$, typical for titanium sub-oxide. RBS investigation showed a stoichiometric ratio of the films of $\mathrm{TiO}_{1.85}$. XRD analysis did not indicate any crystalline phase in these films. Cyclic voltammetric sweep experiments were performed to study the electrochemical behavior of nickel oxide electrodes doped with titanium sub-oxide. Figure 6 shows that the oxygen-evolution reaction was indeed suppressed - its onset potential was shifted by $50-100 \mathrm{mV}$ positive to the nickel oxidation reaction. 


\section{Conclusions}

Cathodic arc deposition is an efficient method for forming strongly adherent coatings of metal oxides with very low contamination and on a large scale. It is an environmentally clean method in comparison to wet-chemical processes because no chemical waste is produced. The films are also cleaner from the chemical point of view, leading to superior UHV compatibility. The films as deposited at room temperature are generally amorphous. They can contain small crystalline structures when the deposition was performed at elevated temperature. Post-deposition annealing modifies the structure of the films and allows the formation of polycrystalline phases. Superior adhesion of the films and mechanical stability during thermal cycling is achieved by combining cathodic arc deposition with pulsed biasing, particularly for conducting substrates. It is possible to deposit chemical compounds such as oxides and nitrides as well as pure or alloy metal films using the same type of plasma source, illustrating the versatile nature of this device-fabrication technique.

\section{Acknowledgments}

This work was supported by the U. S. Department of Energy, Division of Advanced Energy Projects, and the Assistant Secretary for Energy Efficiency and Renewable Energy, Office of Building Technologies, Building Systems and Materials Division of the U.S. Department of Energy, under Contract NO. DE-AC03-76SF00098. 


\section{References}

[1] P. J. Martin, R. P. Netterfield, T. J. Kinder, and L. Descôtes, Surf. Coat. Technol. 49 (1991) 239.

[2] A. Ben-Shalom, L. Kaplan, R. L. Boxman, S. Goldsmith, and M. Nathan, Thin Solid Films, 236 (1993) 20.

[3] A. Anders, S. Anders, I. G. Brown, and I. C. Ivanov, Mat. Res. Soc. Symp. Proc., 316 (1994) 833.

[4] S. Anders, A. Anders, and I. G. Brown, J. Appl. Phys., 74 (1993) 4239.

[5] S. Anders, A. Anders, and I. G. Brown, J. Appl. Phys., 75 (1994) 4895.

[6] A. Anders, S. Anders, and I. G. Brown, J. Appl. Phys., 75 (1994) 4900.

[7] A. Anders, S. Anders, and I. G. Brown, Plasma Sources Sci. Technol., 4 (1995) 1.

[8] A. Anders, S. Anders, I. G. Brown, M. R. Dickonson, and R. A. MacGill, J. Vac. Sci. Technol. B, 12 (1994) 815.

[9] A. Anders, S. Anders, I. G. Brown, and I. C. Ivanov, Mat.Res. Soc. Symp. Proc., 316 (1994) 833.

[10] R. A. MacGill, S. Anders, A. Anders, R. A. Castro, M. R. Dickinson, K. M. Yu, and I. G. Brown, Surf. Coat. Technol., to be published.

[11] M. Rubin, J. Vac. Sci. Technol. A, 10 (1992) 1905.

[12] K. Miyake, H. Kaneko, M. Sano, and N. Suedomi, J. Appl. Phys., 55 (1984) 2747.

[13] J. T. Boyd, Ed., Integrated Optics: Devices and Applications, IEEE, New York, 1990.

[14] M. Federighi, I. Massarek, and P. F. Trwoga, Electr. Lett., 30 (1994), 1277.

[15] M. Oguma, T. Kitagawa, K. Hattori, and M. Horiguchi, IEEE Phot. Tech. Lett., 6 (1994) 1041.

[16] M. P. Miller and J. C. Wright, J. Chem. Phys., 71, (1979), 324.

[17] P. N. Favennec, H. L'Haridon, M. Salvi, D. Moutonnet, and Y. Le Guillou, Electron. Lett., 25, (1989) 718 . 
[18] V. E. Henrich and P. A. Cox, The Surface Science of Metal Oxides, Cambridge University Press, 1994. 


\section{Captions for Figures}

Fig. 1: Kicker electrode and kicker housing after deposition and removing of masks. The black copper oxide coating is visible on the outside of the electrode (left) and inside the housing (right).

Fig. 2: Spectral transmittance of a $\mathrm{WO}_{3}$ film on ITO coated glass in the bleached and colored state. The film thickness was $50 \mathrm{~nm}$.

Fig. 3: Photoluminescence spectrum at room temperature of a $300 \mathrm{~nm}$ thick $\mathrm{Al}_{1.55} \mathrm{Er}_{0.45} \mathrm{O}_{3} / \mathrm{Si}$ structure. The excitation wavelength was $488 \mathrm{~nm}\left(\mathrm{Ar}^{+}\right.$ion laser $-200 \mathrm{~mW}$ ).

Fig. 4: $\mathrm{XRD}$ pattern of $\mathrm{Al}_{2} \mathrm{O}_{3}$ film as deposited on $\mathrm{FeAl}$. The film thickness was $600 \mathrm{~nm}$.

Fig. 5: XRD pattern of the $\mathrm{Al}_{2} \mathrm{O}_{3}$ film of Fig. 4, after 16 hours of annealing at $1000^{\circ} \mathrm{C}$.

Fig. 6: Cyclic voltammetry for Ni electrodes with and without titanium sub-oxide coating. The overpotential for oxygen evolution increases by about $50-100 \mathrm{mV}$ for the sample with coating. 


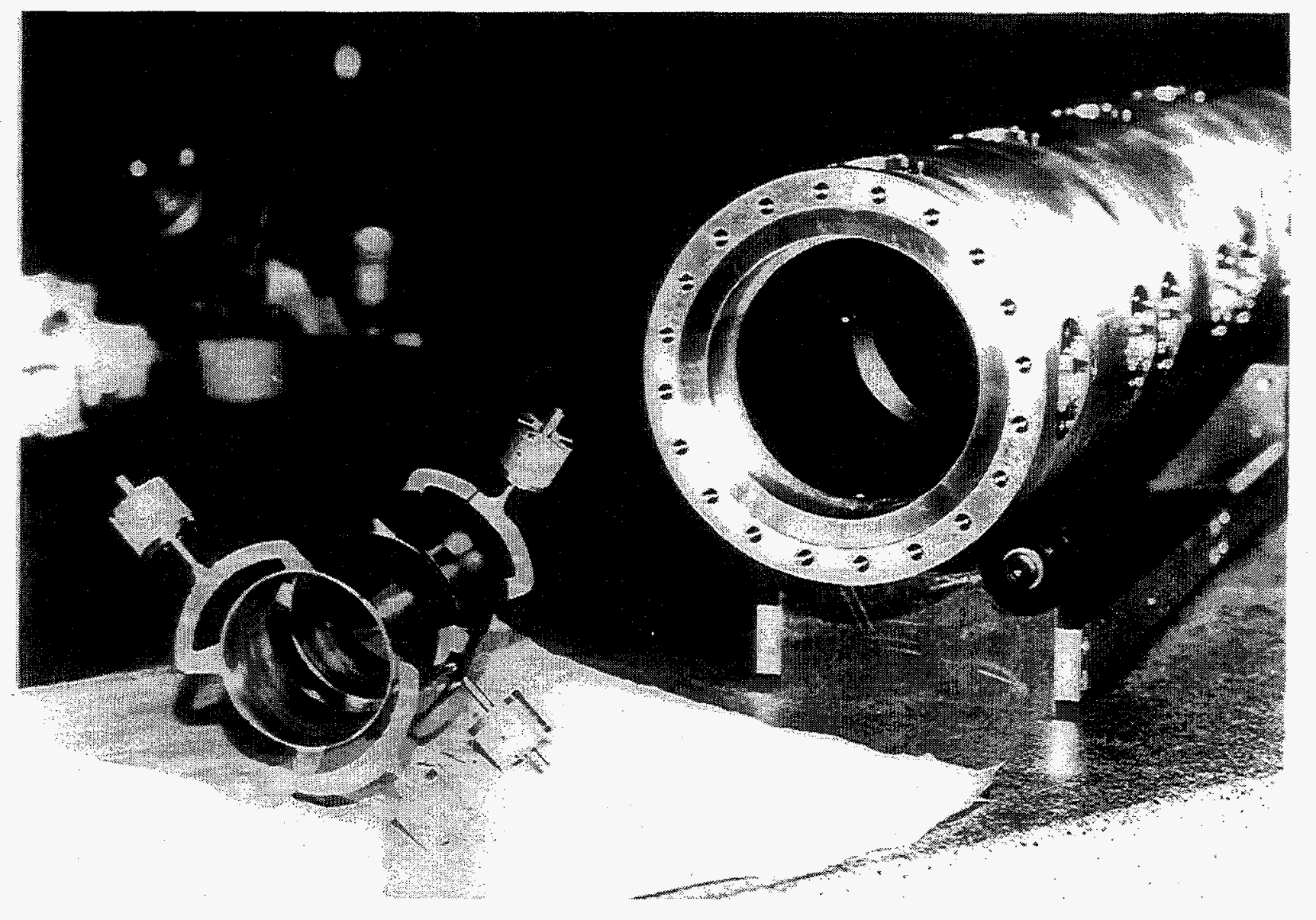

Fig. 1 


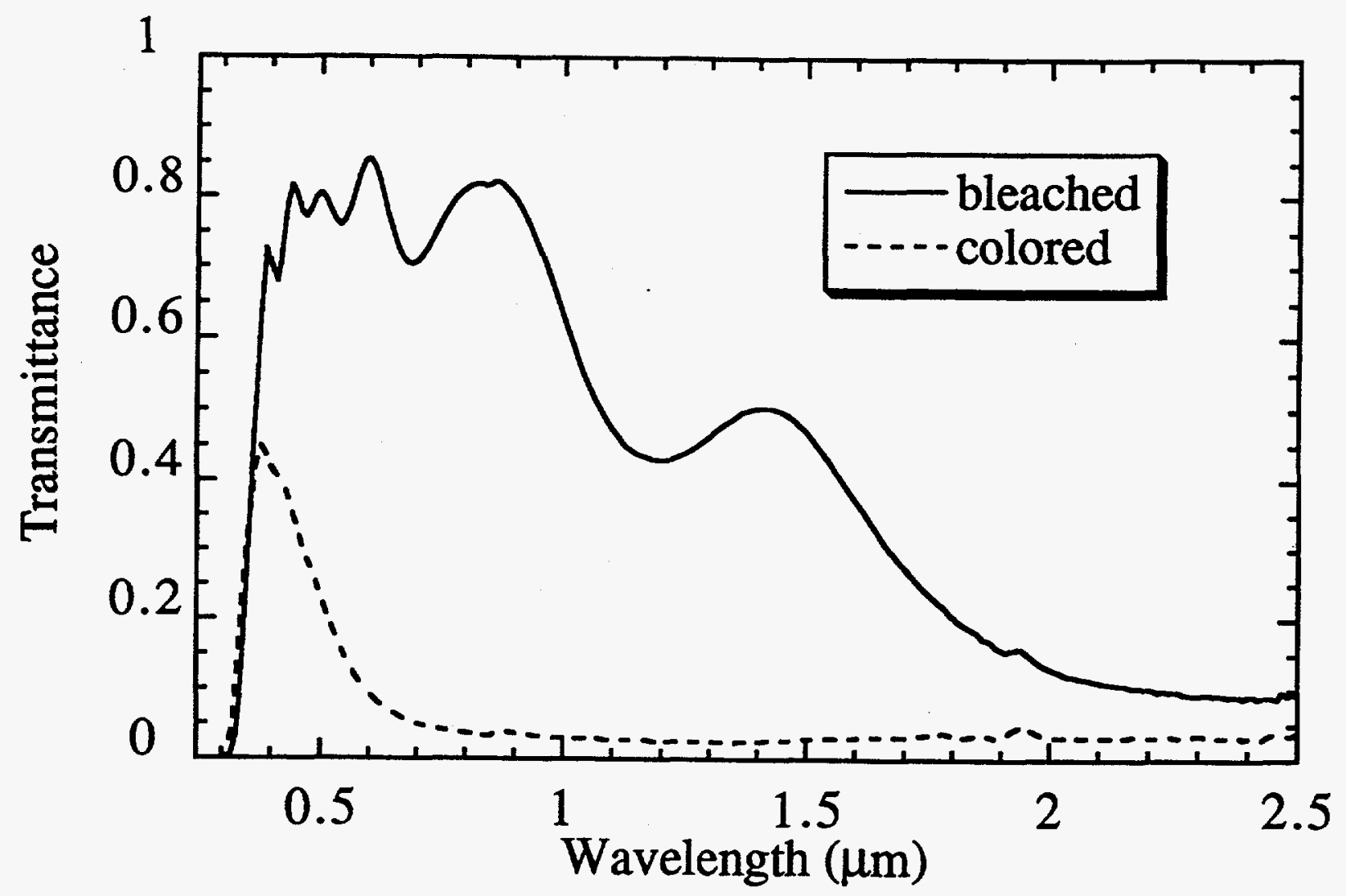

Fig. 2 


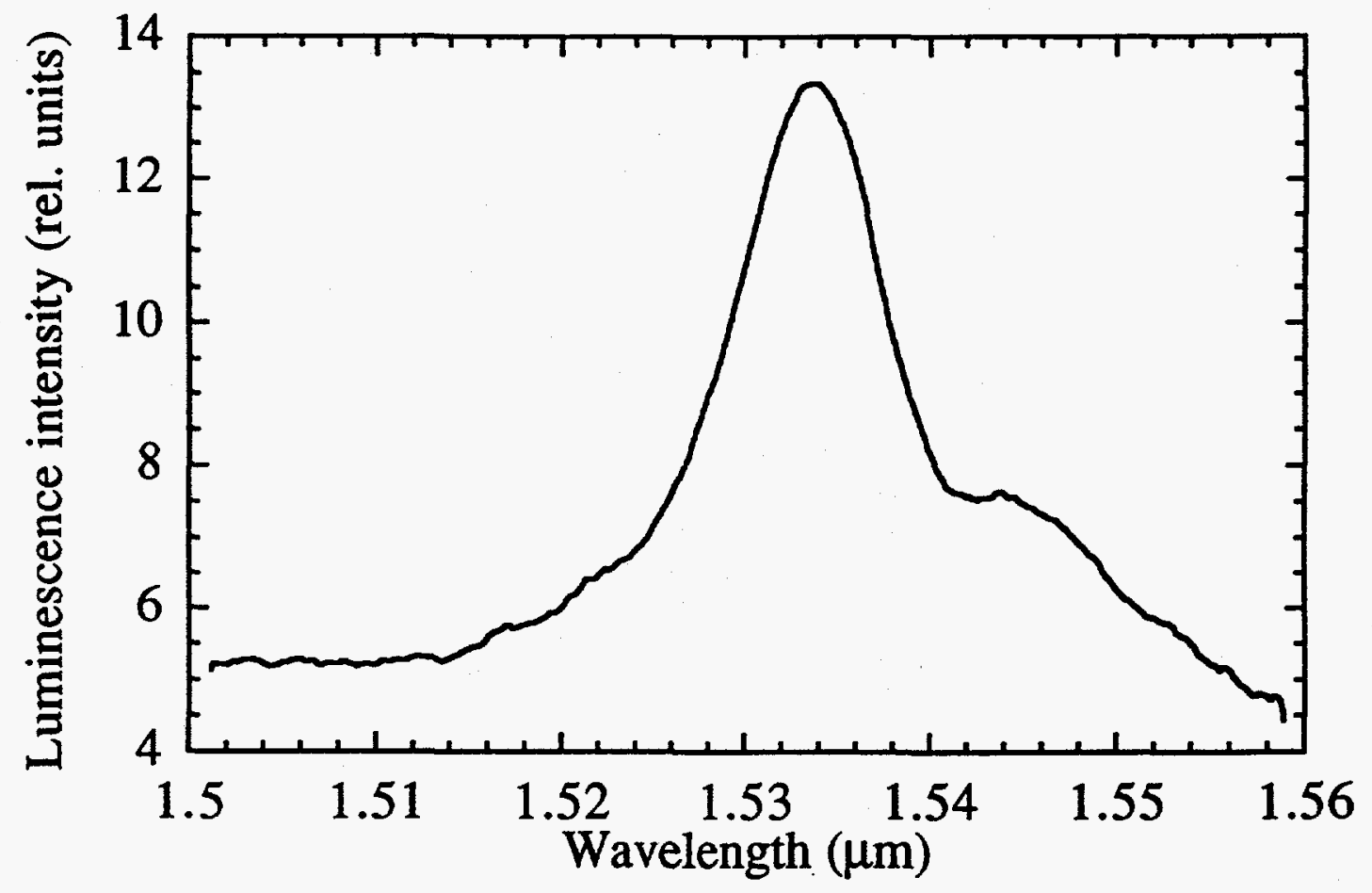

Fig. 3 
Intensity (rel. units)

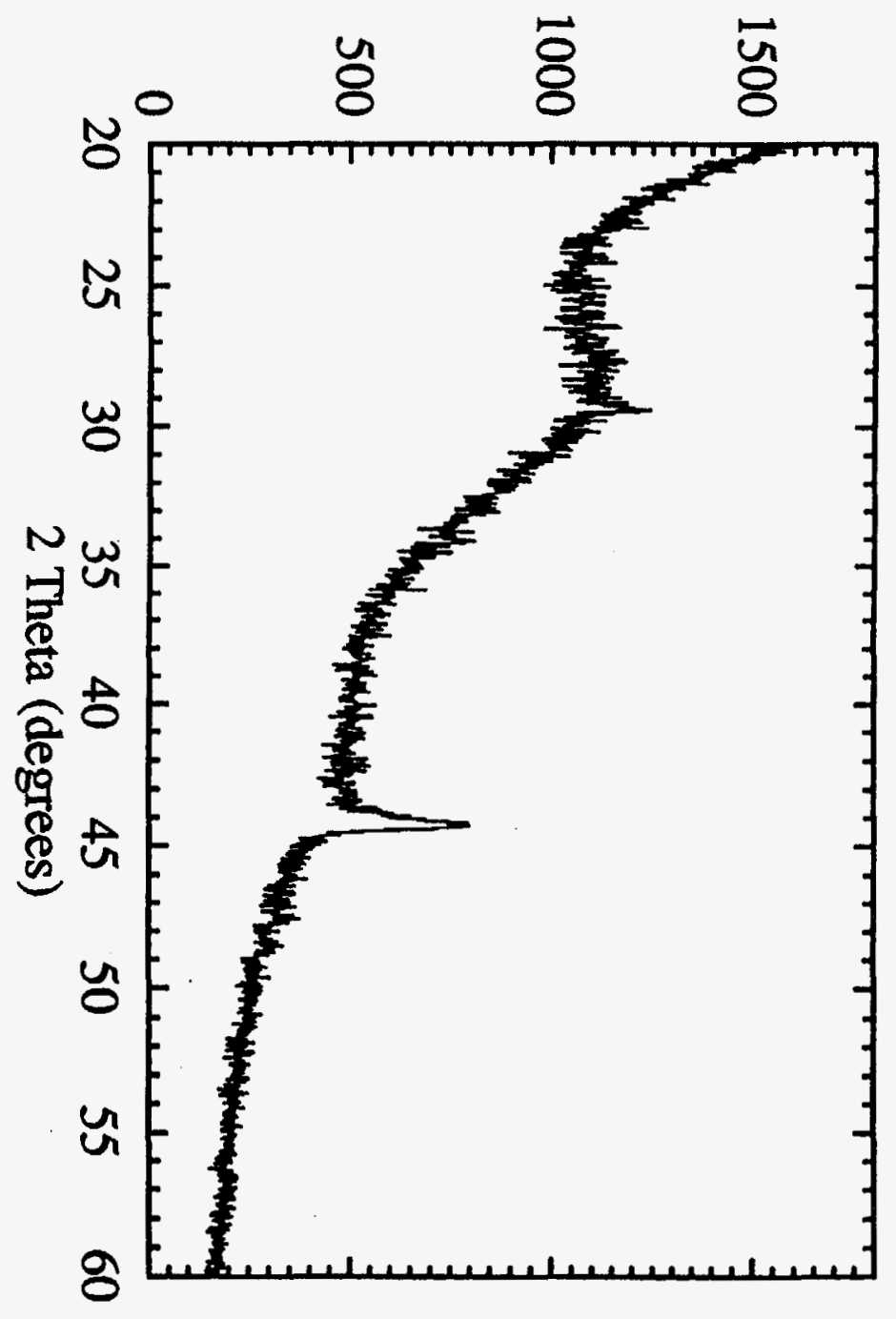




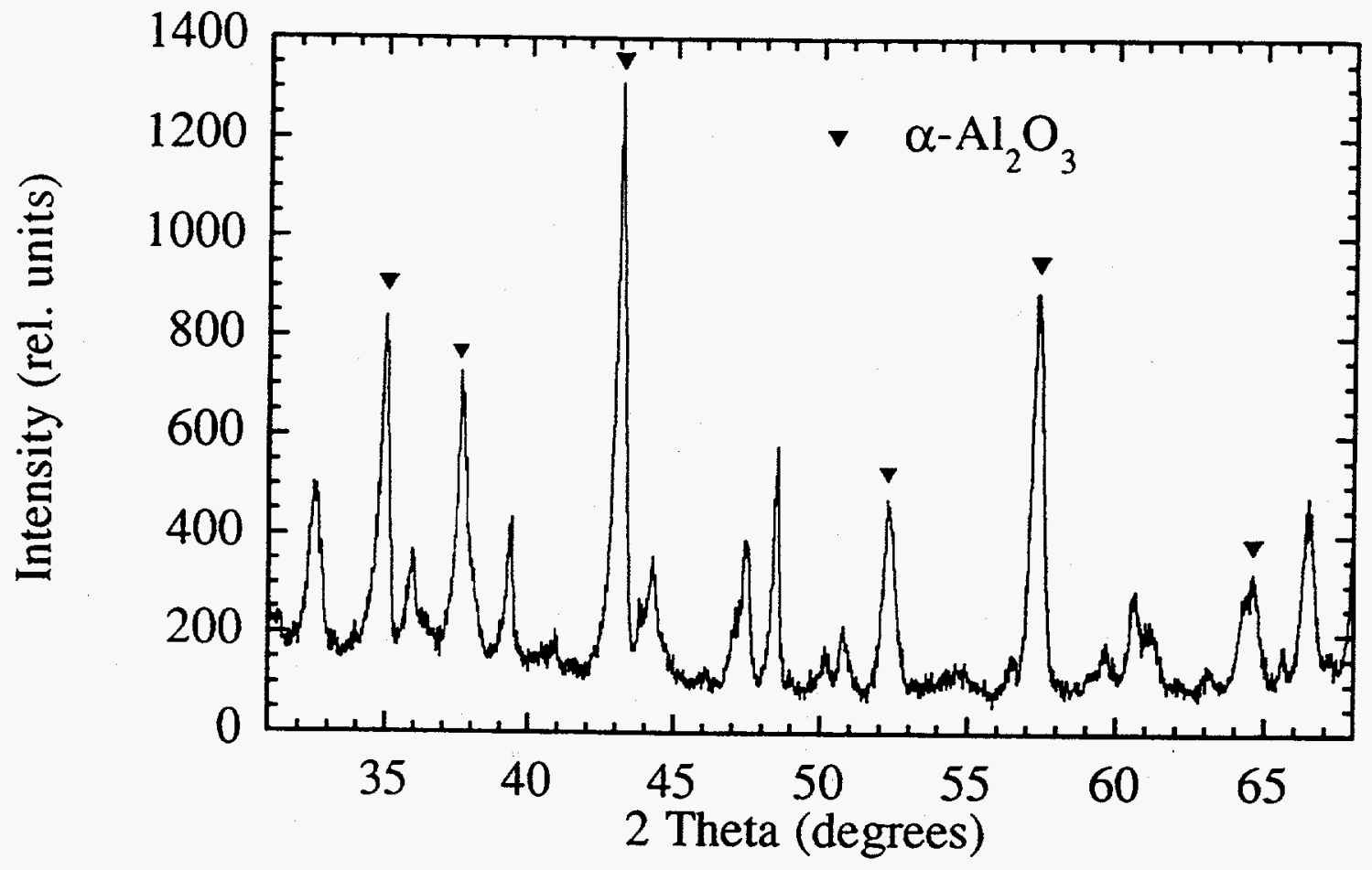

Fig. 5 


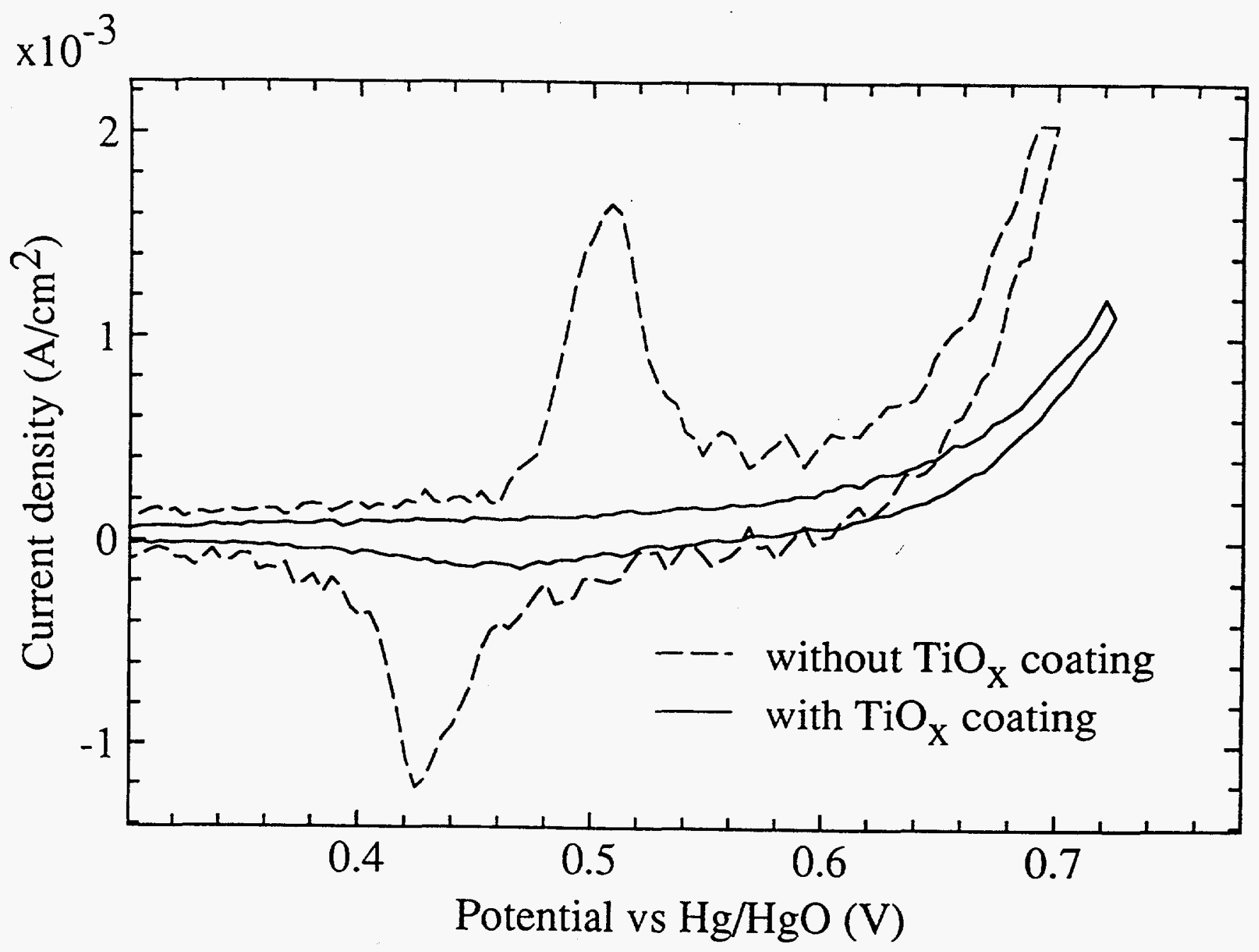

Fig. 6 